\title{
Baby boomers' mobility patterns and preferences: What are the implications for future transport?
}

Siren, Anu Kristiina; Haustein, Sonja

Published in:

Transport Policy

Link to article, DOI:

http://dx.doi.org/10.1016/j.tranpol.2013.05.001

Publication date:

2013

Document Version

Publisher's PDF, also known as Version of record

Link back to DTU Orbit

Citation (APA):

Siren, A. K., \& Haustein, S. (2013). Baby boomers' mobility patterns and preferences: What are the implications for future transport? Transport Policy, 29, 136-144. https://doi.org/10.1016/j.tranpol.2013.05.001

\section{General rights}

Copyright and moral rights for the publications made accessible in the public portal are retained by the authors and/or other copyright owners and it is a condition of accessing publications that users recognise and abide by the legal requirements associated with these rights.

- Users may download and print one copy of any publication from the public portal for the purpose of private study or research.

- You may not further distribute the material or use it for any profit-making activity or commercial gain

- You may freely distribute the URL identifying the publication in the public portal 


\title{
Baby boomers' mobility patterns and preferences: What are the implications for future transport?
}

\author{
Anu Siren*, Sonja Haustein ${ }^{1}$ \\ Department of Transport, Technical University of Denmark, Bygningstorvet 115, DK-2800 Kgs. Lyngby, Denmark
}

\section{A R T I C L E I N F O}

Keywords:

Baby boomers

Older road users

Travel behavior

Travel demand

Aging society

Segmentation

\begin{abstract}
A B S T R A C T
The demographic grand challenge of population ageing will be reflected in most areas of society and, to a great extent, in the area of transportation as well. It will have an impact on, for example, travel demand, infrastructure needs, traffic safety and the climate. The post-World War II cohorts, the so-called "baby boomers", will comprise a large share of tomorrow's older population, and it is expected that they will differ from their parents' generation when they grow old. In order to better understand how the ageing baby boomers may affect future travel demand, the travel behaviour and expectations of Danish baby boomers were analysed based on 1772 standardised telephone interviews. In general, the baby boomers reported being healthy, independent and highly (auto)mobile. They were also optimistic regarding their level of mobility, capability to use a variety of travel modes and ability to lead an independent life in the future. However, there were significant gender differences in terms of present and expected car use in old age, which were somewhat similar to those observed in older cohorts. In addition, different sub groups of baby boomers could be identified based on their future expectations: the so-called Flexibles, Independents and Restricted subjects. The segments showed significant differences in current travel behaviour and living conditions, as well as some similarities to former segments of older road users. The results indicate that the baby boomers are likely to be strong consumers of the transport system also as they age, but that the group is also heterogeneous. Thus, overly optimistic scenarios about independent baby boomers who differ from the previous generations and whose need for external support in old age will be minimal may be unrealistic.
\end{abstract}

(c) 2013 Elsevier Ltd. All rights reserved.

\section{Introduction}

The population is ageing rapidly in all industrialised countries. In Europe, the number of older persons as a share of those of working age, will double between 2010 and 2050 according to Eurostat projections (Lanzieri, 2011). In Denmark, the proportion of people aged 65 and older is increasing steadily and is expected to be around $24 \%$ of the total population in 2040 (Statistics Denmark, 2011). This demographic grand challenge will be reflected in most areas of society and, to a great extent, in the area of transportation (Coughlin, 2009). The changing demographic composition of road users will have an impact on, for instance, travel demand, infrastructure needs, traffic safety and the climate.

The research conducted over the past 15-20 years has contributed significantly to our knowledge about mobility and travel behaviour in old age. Various studies have shown that with age,

\footnotetext{
* Corresponding author. Tel.: +4545256517.

E-mail addresses: aks@transport.dtu.dk, anu.siren@gmail.com (A. Siren), sonh@transport.dtu.dk (S. Haustein).

1 Tel.: +4545256519.
}

and especially after retirement, travel activity tends to decrease, that older persons use private cars less often for transportation compared to other age groups and that, in general, daily activities outside the home tend to decrease with increasing age (e.g. Rosenbloom, 1995; Páez et al., 2007). In recent years, however, we have seen a growth in the travel activities of older people as new successive cohorts have entered old age. Research has indicated increase in licensing rates, car access and car use, number of daily trips and leisure travel (e.g. Arentze et al., 2008; Hjorthol et al., 2010; INFAS and DLR, 2010; Miranda-Moreno and Lee-Gosselin, 2008; Newbold et al., 2005; Ottman, 2010; Rees and Lyth, 2004; van den Berg et al., 2011).

The post-World War II cohorts, the so-called "baby boomers", will comprise a large share of tomorrow's older population. In Denmark, similarly to other industrialised countries, an increased birth rate was observed in the years 1943-1950. Today, the 1943-50 cohorts make up $44 \%$ of the Danish population aged 60 and above (Statistics Denmark, 2011). Over the next five years, most of these people will retire from their jobs, and the youngest of them will reach the Bismarckian "old age" milestone as they turn 65 . We know, however, that the baby boomers are unlikely to resemble their parents' generation, and that their life course has been shaped 
rather differently from that of their parents. For example, they have benefited from the development of the welfare system (including pension schemes), healthcare innovations and economic growth (e.g. Keister and Deeb-Sossa, 2001). They have also gained formal education to a much greater extent than their parents' generation (Eurostat, 2011) and due to the size of their cohort, they have had a large critical mass in society and consequently much more political and societal power (e.g. Dychtwald, 1999).

In terms of travel and mobility, they were the first generation to be born into and live their whole lives in a society with modern mobility, characterised by automobility and long-distance leisure travel (Coughlin, 2009). Consequently, when entering into old age, the baby boomers are likely to differ from their parents or grandparents: they are healthier, lead more active lifestyles, with different consumption patterns, attend various leisure activities, travel more often and over longer distances and have more economic resources (e.g. Moschis and McArthur, 2007). Previous analyses on travel related variables in different age groups over time have indicated higher travel activity, licensing rates, car access and car use among the baby boomers compared to older cohorts (e.g., Hjorthol et al., 2010; INFAS and DLR, 2010; MirandaMoreno and Lee-Gosselin, 2008; Newbold et al., 2005; OECD, 2001; Ottman, 2010; Rees and Lyth, 2004).

Altogether, it is expected that the ageing baby boomers will have a significant impact on the transportation system as they age, but it is less clear what the impact will be. As Joseph Coughlin notes in his review paper from 2009, "it is not just who the baby boomers are but what they will be doing tomorrow that is going to shape future travel demand" (p. 303). While the characteristics of the boomers may predict increased mobility in the future, the future travel demand will be a result of desired mobility and activities the boomers may wish to carry out. In order to get a better indication about the future, the focus should be directed to the future activities and expectations about these. To our knowledge, only one study has previously addressed baby boomers' expectations and intentions as a basis for future forecasts (Hakamies-Blomqvist et al., 2005). This explorative study pointed out the expected car-reliance among the Swedish boomers and the notable differences between men and women.

In addition to the scarce knowledge on boomers' future intentions, the composition of the group raises uncertainties that make forecasting travel demand difficult. First, the future behaviour of boomer women is an important factor shaping the future travel demand. The gender roles and gendered activities have changed tremendously during the boomers' life time, and the boomer women's activities and resources are likely to be different from their mothers'. Second, the boomers are a heterogeneous group with different segments that vary in terms of their resources, consumption, attitudes and values, and this is likely to be reflected in the groups' travel as they age.

At present, older women and men differ greatly in their travel frequency and modal choices. While older men are more car-reliant, older women tend to cease driving and walk, bike, and travel more often as a passenger in a car or public transport (e.g., Rosenbloom, 2006). It is in general expected that the gender differences in travel patterns in old age will decrease or even disappear as the baby boom cohorts grow old. The women in the new cohorts are practically all licensed as drivers and use the car actively. Nevertheless, some researchers have pointed out the persistent gendered, cultural meanings attached to cars and driving, as well as the qualitatively and quantitatively different driving experience women and men gain, which are likely to affect car driving in old age (Hakamies-Blomqvist et al., 2005; Rosenbloom, 2007; Rosenbloom and Herbel, 2009; Siren, 2005; Siren and Hakamies-Blomqvist, 2005).

While the current state of the art in senior travel patterns is increasingly acknowledging the heterogeneity of the older population and that it varies in terms of age, functionality and economic resources, it has largely overlooked the fact that baby boomers, too, are a heterogeneous group. Several previous studies on older seniors have applied segmentation approaches, identifying distinctive subgroups either focussing on sociodemographic variables (Hildebrand, 2003), mobility-related attitudes (Haustein, 2012; Haustein et al., 2008), or mobility behaviour (Aigner-Breuss et al., 2010; Mollenkopf et al., 2004; Rudinger and Käser, 2007) as constituent variables. However, the previous studies on baby boomers have focused primarily on the more general characteristics of these cohorts and highlighted especially the ways in which they differ as a group from other cohorts. This has resulted in general conclusions about high levels of independent mobility and very high car dependency in the future, for example. However, the extent to which these are descriptions of "Barbie and Ken ageing" is unclear-that is, descriptions of resource-strong, middle-class boomers who will, on average, be leading independent lives into very old age, without any need for external support.

The general aim of the present study is to examine baby boomers' past and present travel behaviour, expectations for the future, heterogeneity and the implications that these factors may have in terms of the future travel. More specifically, the present study aims to describe the travel patterns and preferences, car reliance, and future expectations of the baby boom cohort in Denmark, with an explicit focus on gender differences and the heterogeneity of the group. A central question of the study is also how the boomers' present activities and future expectations may shape the future transport.

\section{Method}

\subsection{Sample and procedure}

Data for this study were collected from November 2009 to December 2009 by means of standardised computer-assisted telephone interviews (CATI) carried out by Synovate Denmark A/S. To obtain a representative sample of baby boomers, a random sample of citizens born in 1946 and 1947, i.e. in the peak years of the baby boom, was drawn from the Danish person register. The target population received a letter announcing the survey.

Altogether, 1772 interviews were conducted. After correcting for telephone/address errors, people who were unable to be interviewed due to language barriers or illness and people who were not contacted because the number of intended interviews had already been achieved, the overall response rate was $74 \%$ (15\% refusals, $12 \%$ not reached).

The respondents consisted of 892 women and 880 men, aged 62 (50.1\%) and 63 (49.1\%; 1946 and 1947 cohorts). Most of the respondents had a spouse ( $80.2 \%$ were married or cohabitating), while $13.3 \%$ were single and $6.5 \%$ widowed. The sample was representative in terms of gender, income and family status, whereas the educational level of the sample was somewhat above average (see Table 1 ). This is probably due to a higher willingness to participate among well-educated people.

Table 1

Sample descriptive compared to census data from Statistics Denmark.

\begin{tabular}{lll}
\hline & Statistics Denmark & Sample \\
\hline Women & $50.1 \%$ & $50.3 \%$ \\
Basic school education & $31.6 \%$ & $19.2 \%$ \\
Higher education & $20.0 \%$ & $32.7 \%$ \\
Widowed & $6.6 \%$ & $6.5 \%$ \\
Average income & 40,100 EUR & 38,200 EUR \\
\hline
\end{tabular}




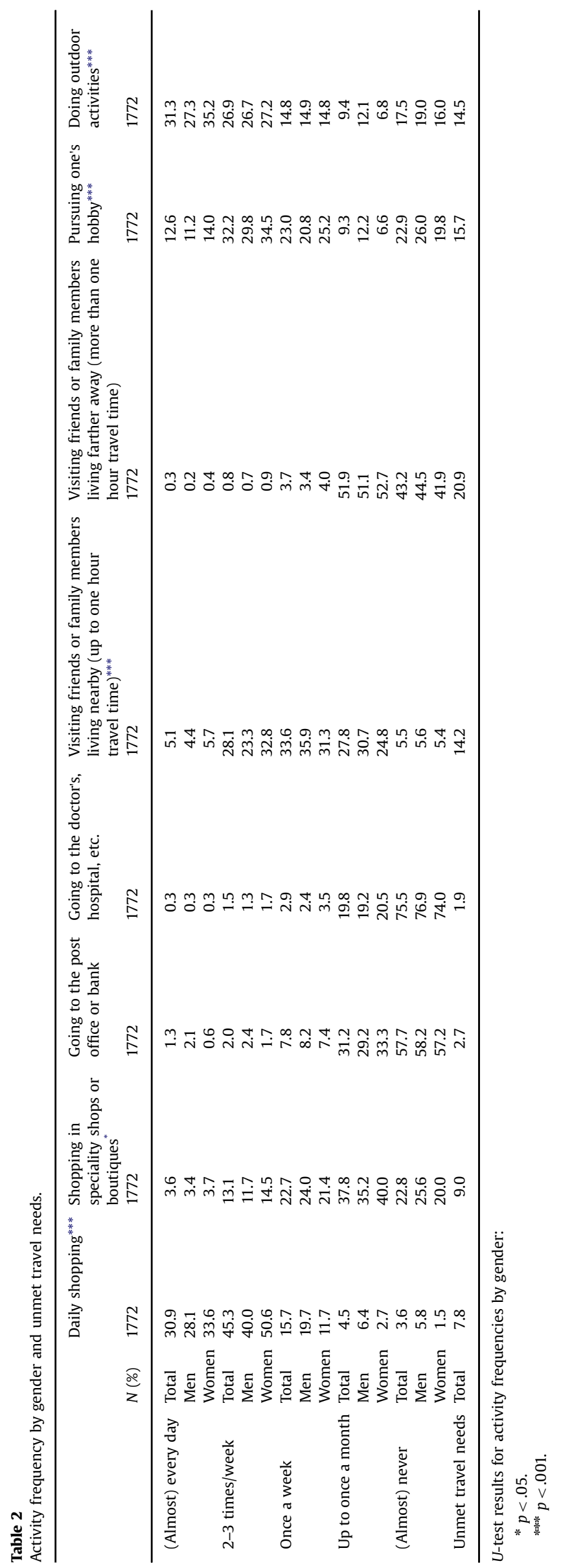

The respondents were generally healthy and well functioning. They described their health, on average, as somewhere between good and excellent ( $M=1.6$ on a four-point scale), and only $1.5 \%$ assessed their health as being "poor" and 7.5\% as "fair." The most common symptoms and health conditions reported were hypertension (35.0\%) and painful joints (29.4\%). All other symptoms and health conditions played a minor role, being mentioned by less than $10 \%$ of the sample.

\subsection{Measures}

The standardised interviews were based on an ad hoc questionnaire. The interviews took an average of $25 \mathrm{~min}$ to complete and included questions on background information, mobility patterns, driving habits and future expectations. In the following section, the parts of the questionnaire which are analysed in the present article are described in detail.

Background information. Included gender, education, family status (married/living with a partner, single, widowed), personal income and health status. As an objective measure of health status, the participants were presented with a list of 20 symptoms and illnesses and asked to indicate whether they suffered from these as confirmed by a physician. This list was derived from previous studies with a similar setting and subjects (e.g. Siren et al., 2004). In addition, the participants were asked to rate their overall health on a four-point rating scale ("excellent," "good," "fair" and "poor").

Car use and access individuals were asked whether they had a driving license, their annual mileage today and 10 years ago, their driving frequency and their access to a car (as a driver). Driving frequency was assessed with a six-point rating scale ranging from "every day" to "never."

Modal choices and transport patterns were assessed by participants' specifications about different everyday activities (see Table 2 for the list of activities). Individuals were asked about the activity frequency (six-point scale from "[almost] never" to "[almost] every day") and the most common mode of transport for each activity. To obtain information about unmet travel needs, they were further asked if they wished to perform the activities more often ("a lot more often"; "somewhat more often"; "not more often"). Participants were also asked who chauffeured them most frequently and who they chauffeured most frequently. The alternatives presented included their spouse, children or grandchildren, other family members, friends and people whom they did not know personally.

Finally, respondents were asked how dependent they were on others when they wanted to go out (on a four-point rating scale ranging from "very dependent" to "not at all dependent").

Future expectations were assessed by asking the respondents to imagine themselves at the age of 80 . They were then asked to evaluate the probability of nine different statements. The statements referred to the use of different modes of transport (e.g. "I am driving a car"), general living conditions (e.g. "I am living in the same location as now") and their level of dependency on others (e.g. "I am leading an everyday life without help from others"). The list of statements was adapted from a Swedish study with similar setting and subjects (Hakamies-Blomqvist et al., 2005).

\subsection{Analysis}

In order to test the statistical significance of gender differences in baby boomers' travel behaviour and their expectations for the future, we used Pearson's $\chi^{2}$ test, Mann-Whitney $U$-test, KruskalWallis $\mathrm{H}$-test and ANOVAs as appropriate.

We used cluster analysis to explore the heterogeneity of the respondents and to identify sub-groups according to future expectations. This method generally does not offer a way to 


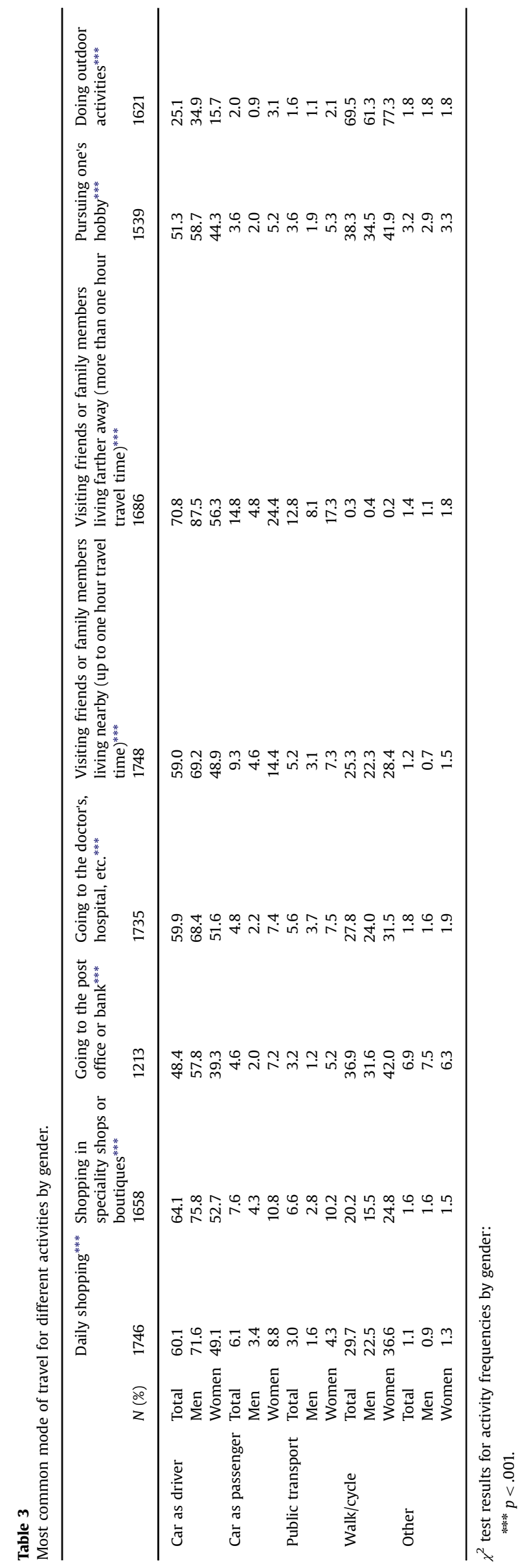

calculate the optimal number of clusters and thus, we conducted cluster analyses using the $k$-means algorithm for two to five cluster solutions. We compared the solutions according to the criteria of predictive power and interpretability. In order to assess predictive power, an external criterion variable had to be chosen, which was the frequency of car use. We tested differences between clusters for significance with the same parametric and non-parametric tests as used for gender analyses.

\section{Results}

\subsection{Travel patterns}

\subsubsection{Car use and access}

More than $90 \%$ of the respondents were licensed drivers. There was a small gender difference: a larger share of men than women held a license $\left(95.1 \%\right.$ and $88.7 \%$, respectively; $\chi^{2}(2,1772)=45.92$, $p<.001$ ). Overall, $90.9 \%$ of the respondents had access to a car in their household. Of the men, $92.8 \%$ reported having a car in the household, compared to $88.9 \%$ of women, $\chi^{2}(3,1772)=9.03, p<.05$.

The differences between men and women were more pronounced in terms of car use: $91.4 \%$ of men holding a license reported driving a car daily or several times a week, compared to $76.0 \%$ of women. Of the female license holders, $9.0 \%$ reported not driving at all, compared with $3.0 \%$ of men. The gender differences in the frequency of car use were statistically significant, $U(1628)=242641, p<.001$. In addition, men's annual mileage was higher than women's $(17,944 \mathrm{~km}$ and $11,038 \mathrm{~km}$, respectively; $F(1,1542)=153.33, p<.001)$. Both men and women reported, on average, a decline in the number of kilometres they drove annually compared to 10 years ago. Men once again reported higher annual mileage than women $(22,494 \mathrm{~km}$ and $14,565 \mathrm{~km}$, respectively; $F(1,1520)=114.81, p<.001)$. However, when comparing the annual mileage from 10 years ago and today on the individual level, we found that while $43 \%$ of the respondents had decreased their mileage during the last 10 years, $40 \%$ had stayed at the same level and $17 \%$ had increased their mileage. When we compared these three groups according to background variables, gender and transport habits, there were no differences between them, with the exception of driving frequency, $H(2,1599)=14.87, p<.01$.

\subsubsection{Modal choices and transport patterns}

For each everyday activity, the respondents indicated how often they participated in these activities and which mode of transportation they used most often. As Table 2 shows, the most frequent activity for both men and women was daily shopping, followed by outdoor activities. Women reported a higher frequency of shopping trips as well as a higher amount of different leisure time activities. Majority of participants did not express unmet travel needs (see Table 2). However, in the case of most of the activities, a small share of the respondents did indicate unmet needs. As regards daily shopping, $8 \%$ of the respondents indicated unmet needs, which might have an important impact on their daily lives. Visiting friends living farther away was an activity more generally affected by unmet travel needs as about $20 \%$ of the participants wished to do this more often. This was the only activity where a small gender difference was observed (women: 22.8\%; men: $\left.19.0 \% ; \chi^{2}(2,1772)=6.15, p<.05\right)$.

As Table 3 shows, the car was the mode of transportation which was used most frequently for all activities except outdoor activities, for which walking or cycling was more popular. Another activity for which the respondents often walked or cycled was going to the post office or bank. Using public transport as a primary mode was rather unusual. Only with regard to visiting friends or family members who live farther away did more than $10 \%$ of the respondents report using public transport as their 
primary mode of transportation. Here, travelling as a passenger in a car was also important. This may not be surprising, as this is less likely to be conducted alone. Regarding gender differences, we found that for each activity, men used the car as a driver more often than women, who accordingly were more likely to use the other modes ( $p<.001$ for all activities).

Men transported others more frequently than women, even if we only considered licensed persons, $U(1628)=287148, p<.001$. As regards whom the respondents drove around most frequently $\left(\chi^{2}[4,1532]=159.38\right)$ and by whom they were driven most frequently $\left(\chi^{2}[5,1772]=58.07\right)$, men and women differed significantly $(p<.001)$, as illustrated in Fig. 1. While for $70 \%$ of men, their spouse was the person they drove around most often, the share of women who chauffeured their partner around was only $38 \%$. Approximately $25 \%$ of women reported driving their children or grandchildren around most often, and 18\% reported driving their friends. Women reported being driven around by their partner most frequently, and a larger share of men than women reported not being driven around at all by other people.

Regarding dependency on others for going out, the majority of the respondents reported being independent (82.9\%). However, more women than men reported being to a greater or lesser extent dependent on others $\left(14.7 \%\right.$ vs. $\left.6.8 \% ; \chi^{2}(3,1772)=29.62, p>.001\right)$.

\subsection{Future expectations}

\subsubsection{Descriptive results and gender differences}

The respondents were asked to imagine themselves at the age of 80 and to evaluate the probability of certain scenarios regarding the use of different modes of transport and (mobility) services, and the effect of certain living conditions. The nine statements and their evaluation are presented in Table 4. The scenarios evaluated as being the most probable by the respondents were the use of phones and the Internet for bank transactions and cycling and walking, whereas using delivery services was regarded as unlikely by a large share of the respondents. Many respondents also perceived it as being likely that they would be living in the same location, managing their daily life without external help and staying at home most of the time. Driving a car divided the respondents. While many assessed that it was very likely or likely

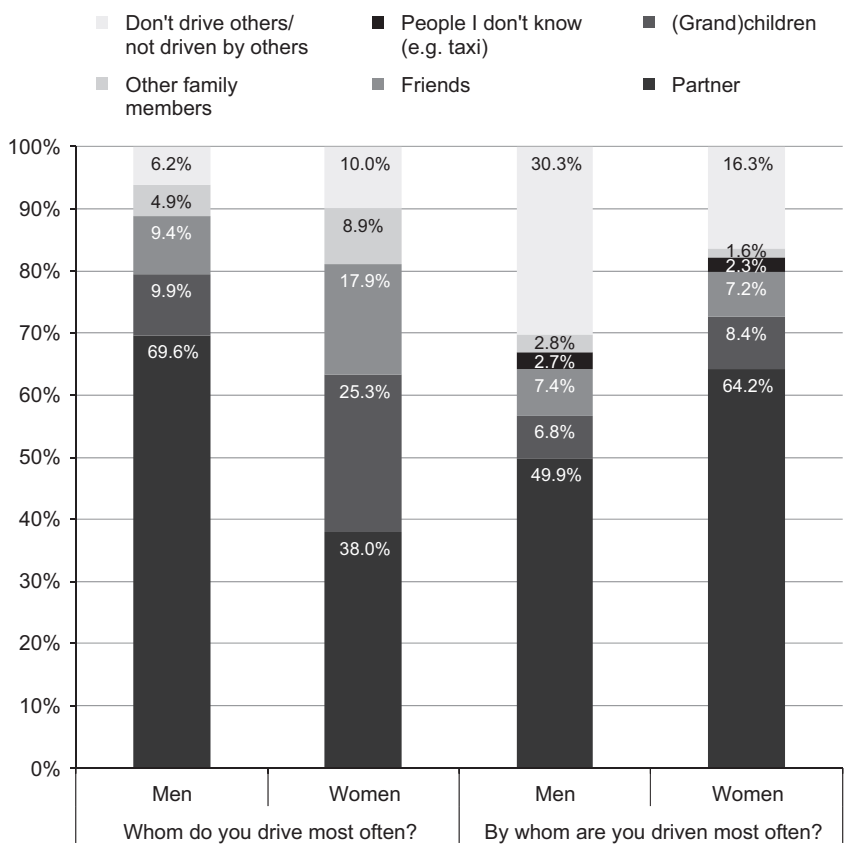

Fig. 1. Chauffeuring and being chauffeured: Percentages by gender. 
that they would be driving at the age of 80 , approximately one third of the respondents evaluated it as being very unlikely.

The gender differences regarding future expectations reflected the differences in current transport patterns. While men, on average, were more likely to expect to be driving a $\operatorname{car}\left(M_{\mathrm{m}}=3.25 ; M_{\mathrm{w}}=4.01\right.$; $F(1,1771)=69.01, p<.001)$, more women expected to be using public transport $\left(M_{\mathrm{m}}=3.53 ; M_{\mathrm{w}}=3.02 ; F(1,1771)=33.79, p<.001\right)$. In addition, compared to women, more men expected to stay at home $\left(M_{\mathrm{m}}=2.27 ; M_{\mathrm{w}}=2.69 ; F(1,1771)=34.54, p<.001\right)$ and carry out banking over the telephone or the Internet $\left(M_{\mathrm{m}}=2.25 ; M_{\mathrm{w}}=2.61\right.$; $F(1,1771)=15.43, p<.001)$.

\subsubsection{Cluster analysis}

We conducted cluster analyses using the $k$-means algorithm for two to five cluster solutions based on the nine future expectation items. First, we compared the four solutions with regard to group differences in an external criterion variable. Table 5 presents the results of ANOVAs for the different cluster solutions predicting the frequency of car use. With the highest $F$-value as well as the biggest increase in the $\mathrm{Eta}^{2}$, the three-cluster solution appears to be superior to the others.

As the second and most important step, we compared the interpretability of the different solutions. The two-cluster solution produced two groups which - besides a big difference in the expected use of delivery services - differed only slightly in the degree of agreement with all of the variables (one group always had slightly lower values). The three-group solution created a third type with a special characteristic, whereas the two former clusters were more specific. Finally, the four-cluster solution merely doubled one former cluster, again with a slightly higher

Table 5

ANOVA results for two to five clusters.

\begin{tabular}{lll}
\hline \multirow{2}{*}{ Number of clusters } & \multicolumn{2}{l}{ ANOVAs (Frequency of car use) } \\
\cline { 2 - 3 } & F- value & Eta $^{2}$ \\
\hline 2 & 42.70 & .026 \\
3 & 49.20 & .057 \\
4 & 38.39 & .066 \\
5 & 28.45 & .066 \\
\hline
\end{tabular}

degree of agreement. Taking into account both criteria, we selected the three-cluster solution.

Fig. 2 illustrates the cluster profiles of the three-cluster solution. The members of the first cluster expected to use all modes of transport but the car. Furthermore, they expected to be using the Internet or a telephone for banking transactions and - more so than the other groups - to make use of delivery services. Due to their flexibility in their choice of transportation and openness to services, we called them the "Flexibles". Members of the second cluster expected to be using primarily individual modes of transport, i.e. driving a car, cycling or walking. They also imagined using the Internet and telephones for transactions, but no delivery services. Compared to the other groups, they expected to depend on others to a lesser extent and were therefore called the "Independents". Members of the third and smallest cluster expected to be restricted in their use of all modes of transport, and especially in car use. They could neither imagine using delivery services nor the Internet/telephone for transactions. They expected to depend on others to a larger extent than the other two groups and were therefore called the "Restricted" group.

As summarised in Table 6, there were several significant differences between the three groups concerning demographics. Among the car-oriented Independents, men were slightly overrepresented, as were subjects with a higher level of education and income, better health and a partner in their household. The Restricted group, on the contrary, had an overrepresentation of women and persons with a lower level of education and income. In all these aspects, the Independents differed significantly from the Restricted group $(p<.001)$. The Flexibles had the highest level of education, an average income and an almost average gender distribution. They differed significantly from both other groups with regard to health (Scheffe, $p<.05$ ), from the Independents with regard to gender and the presence of a partner in the household $(p<.01)$ and from the Restricted group with regard to educational level $(p<.001)$.

Regarding the car-related variables (see Table 6), Independents had the best car access and highest level of car usage, and they were the least dependent on others in terms of transport. The Restricted group had the lowest level of car access and car use and a higher share reported depending on others for transportation, whereas the Flexibles lay in between the two. Concerning car access, driving frequency and dependency, all groups differed significantly from one another. Regarding license-holding, the

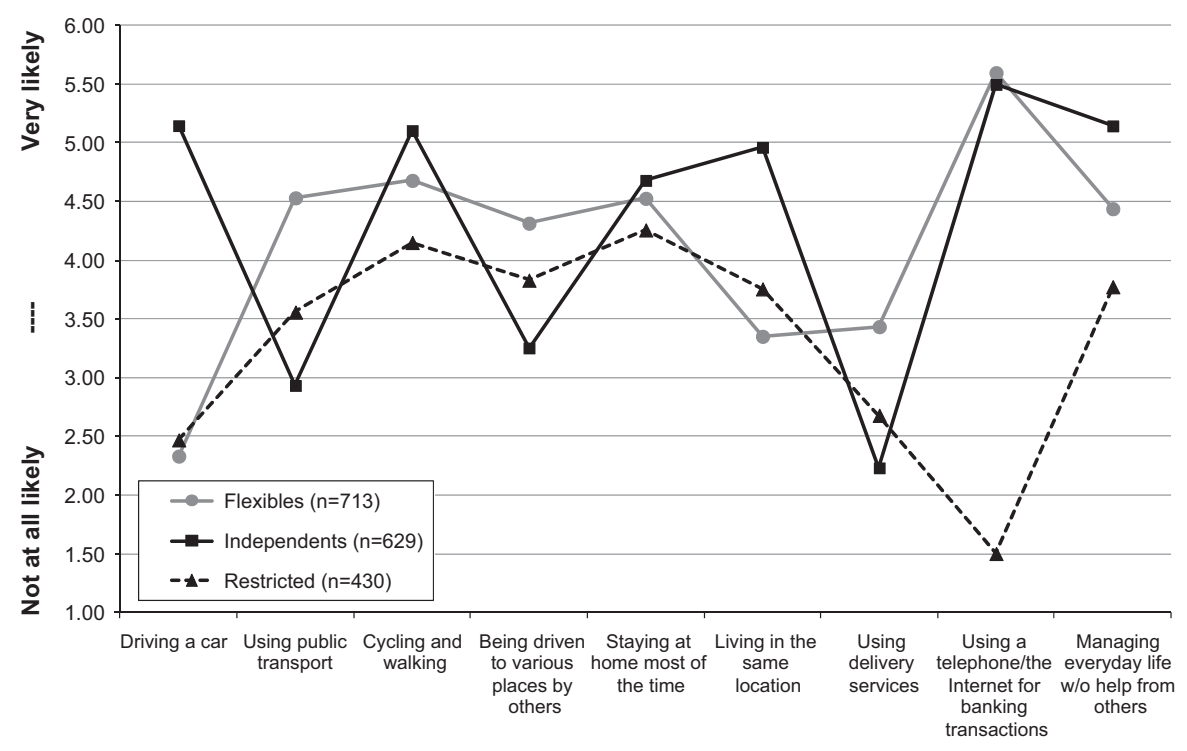

Fig. 2. Cluster profiles and mean values in sub-groups for the assessment of the likelihood of various scenarios. 
Table 6

Description of segments with regard to demographics, health and car-related variables.

\begin{tabular}{|c|c|c|c|c|}
\hline & Flexibles (\%) & Independents (\%) & Restricted (\%) & Test results ${ }^{a}$ \\
\hline \multicolumn{5}{|l|}{ Demographics and health } \\
\hline Men & 46.1 & 58.7 & 41.9 & $\chi^{2}(2,1772)=34.36, p<.001$ \\
\hline Good or excellent health & 90.5 & 95.9 & 85.3 & $F(2,1771)=28.07, p<.001$ \\
\hline Basic school education & 14.0 & 15.9 & 32.8 & \\
\hline Higher education & 39.6 & 36.5 & 15.5 & $H(2,1767)=94.44, p<.001$ \\
\hline Low income quartile ( $\leq 21,000$ EUR/year) & 23.6 & 18.9 & 40.1 & \\
\hline High income quartile ( $>47,000$ EUR/year) & 27.2 & 35.0 & 11.5 & $F(2,1468)=5.09, p<.01$ \\
\hline Living together with a partner & 78.5 & 85.5 & 75.3 & $\chi^{2}(4,1772)=22.97, p<.001$ \\
\hline \multicolumn{5}{|l|}{ Car-related variables } \\
\hline Driving license & 89.5 & 98.6 & 86.0 & $\chi^{2}(4,1772)=62.93, p<.001$ \\
\hline Car in the household & 87.5 & 98.7 & 84.9 & $\chi^{2}(6,1772)=80.48, p<.001$ \\
\hline Driving a car every day ${ }^{\mathrm{b}}$ & 56.3 & 69.0 & 48.9 & \\
\hline Never driving a car & 7.2 & 0.6 & 12.4 & $H(2,1628)=63.92, p<.001$ \\
\hline Driving up to $5000 \mathrm{~km} /$ year $^{\mathrm{c}}$ & 19.3 & 13.2 & 22.8 & \\
\hline Driving more than $20,000 \mathrm{~km} /$ year & 17.6 & 20.8 & 10.1 & $F(2,1542)=16.39, p<.001$ \\
\hline Independent of others & 88.6 & 94.4 & 82.6 & $F(2,1771)=22.29, p<.001$ \\
\hline
\end{tabular}

a Depending on the scale of measurement, $\chi^{2}$ tests, Kruskal-Wallis $H$-tests or ANOVAs were calculated.

${ }^{\mathrm{b}}$ of those with a license.

c Of those with a license and still driving.

Independents differed significantly from both other groups $(p<.001)$, but the Flexibles and the Restricted group did not differ significantly from one another $(p>.10)$. Concerning annual mileage, the Restricted group differed significantly from the Independents and the Flexibles (Scheffe, $p<.001$ ).

\section{Discussion}

The aim of this study was to describe the travel habits, preferences and expectations of the baby boom cohort in Denmark in order to understand how these factors may affect future transport. There were a number of main findings.

First, in general, the baby boomers reported being healthy, independent and highly (auto)mobile, with good access to personal transportation and private cars. Second, while the licensing rates and car access were comparable between women and men, there were significant gender differences in terms of car usage, mileage, modal choices and expectations regarding car usage in old age. Third, the baby boomers reported feeling optimistic regarding their level of mobility, use of different modes of transport and ability to lead an independent life in the future. Finally, there were systematic differences between sub-segments of boomers as regards future expectations.

The fact that the baby boomers studied in the present paper were highly mobile, healthy and independent is in line with the previous literature, which suggests that these cohorts will differ from their parents' generation which until now has formed the reference group for the "older population". Studies comparing the different cohorts of seniors have shown that the licensing rates and car access in the older cohorts were significantly lower and that they travelled less when they were in their 60s compared to the cohorts that are in their 60s now (Hjorthol et al., 2010). This difference at the "baseline" is likely to create different travel patterns also as the boomers reach more advanced old age.

The expectations of the baby boomers were fairly optimistic and reflected an intention to remain active consumers and users of the transport system. They expected to be independent in terms of transport when they were 80 years old, which would mean considerable reliance on cars, and demands of good public transport services and solutions that serve the needs of independent travellers. Coughlin (2009) has suggested that the most striking difference between the baby boomer generation and the previous generations is their expectations regarding ageing and the future.
The expectations about the future are constructed through past experiences (cf. Robins, 1995) and reflect the lived life and the adopted behavioural patterns. While the earlier disengagement theories on ageing suggested a process of ceasing earlier life styles and a withdrawal from the society in old age (Cumming and Henry, 1961), the modern theories suggest continuity in personal life styles within the limits of functionality (Atchley, 1999).

Unforeseen health conditions and functional decline may indeed interfere with boomers' intentions. At present, approximately $28 \%$ of the Danish population aged $80-84$ years receives formal, weekly assistance in their daily lives (Statistics Denmark, 2012), indicating some level of dependency on others. It has been suggested that while boomers are likely to suffer from chronic diseases such as hypertension and diabetes, their disability rates will be lower than their parents', and they will continue leading active life styles and have significant mobility demands (Coughlin, 2009). Thus, on a general level, the expectations and intentions observed here will be likely to affect the actual behaviour of the boomers in the future.

However, the gender differences that we could observe among the baby boomers in the present study indicate that despite high licensing rates and car access, women differ significantly from men with regard to car use, both today and in their expectations for the future. Compared to men, women have significantly lower annual mileage, drive less often and use other modes of transportation more frequently, regardless of the purpose of their trip. In addition, women tend to chauffeur a wider range of other people, while men predominately drive their spouses. Compared to men, women report being chauffeured around more frequently, and being dependent on others for their transport. In terms of their future expectations, women assess that it is less likely that they will be driving a car when they are 80 years old. These gender differences imply that the (auto)mobility of female baby boomers when they grow old may be overestimated if it is based on licensing rates, car access or the baby boomers' average travel patterns. The previous literature has discussed the extent to which older women's travel patterns are changing, with new cohorts entering into old age (e.g. Rosenbloom and Herbel, 2009). It has been proposed that the gender differences might persist, as car driving still bears different cultural meanings for women and for men, and women in younger cohorts still gain qualitatively and quantitatively different driving experience during their life course, which may result in notable gender differences in driving and travel patterns, driving cessation and self-regulatory behaviour in 
old age (e.g. Hakamies-Blomqvist and Siren, 2003; Rosenbloom, 2006; Siren, 2005). On the other hand, the observed gender difference in chauffeuring others suggests that women have transport-related social responsibilities and are, to a large extent, providers of informal mobility care-giving. Previous studies have suggested that women who choose to drive tend to justify their driving with practical reasons (relating especially to family and friends) as opposed to the pleasure of driving (Rosenbloom, 2007; Siren and Hakamies-Blomqvist, 2005). Female baby boomers often provide care to both their (grand) children and their aged parents and are therefore sometimes referred to as the "sandwich generation" (Rosenbloom and Fielding, 1998, p. 91). This may influence women's car usage in their old age and may be an important factor influencing future travel (cf. Coughlin, 2009:304).

Another factor influencing the impact which baby boomers will have on the future transport demand relates to heterogeneity and the different sub-segments of the group. The present study identified three sub-groups with fairly different expectations regarding the future. These sub-groups also differed in terms of their current travel behaviour and living conditions. While the "Independents" reflect the general tendencies of baby boomers with a high level of reliance on cars, and the "Flexibles" reflect the tendency to be open to different modes and services, the "Restricted" group deviate from the general picture. This group's need for external support will probably be much larger than that of the two others. In this sense, the boomers' future needs will probably not differ completely from their parents', and the differences between the "new old" and "old old" in terms of independence and the need for support may be smaller than intuition suggests. This is further supported when this study's findings are compared to previous studies that have identified sub-segments of older people in terms of transport use (AignerBreuss et al., 2010; Haustein, 2012; Hildebrand, 2003). Although these segmentations are not based on future expectations but socio-demographic, attitudinal or behavioural variables, we distinguished similar segments in our study. The "Independents", identified here as a wealthier, more car-oriented group, are comparable to Hildebrand's (2003) "Affluent Males", Haustein's (2012) "Affluent Mobiles", and "people who predominantly use the private car" identified by Aigner-Breuss et al. (2010). The "Flexibles" resemble Haustein's "Self-Determined Mobiles," and AignerBreuss' "selective car users", as active users of various modes of transport. Finally, the "Restricted" group shows similarities to Hildebrand's "Disabled Drivers" and "Mobility Impaired" as well as two segments of restricted people distinguished by Haustein, namely "Captive Car Users" and "Captive Public Transport Users", and Aigner-Breuss' "older people without access to a private car". Although the groups identified in the three former segmentation studies differ in size and their more specific characteristics, the described similarities indicate that the identified sub-groups of baby boomers do not principally differ from other sub-groups of older people and that similar target-group specific measures can be applied to support their mobility needs. While the Flexibles are the least problematic group with openness to shift between different modes of transport, the Independents may be vulnerable to driving cessation, especially if combined with a limited access to a high quality transit that serves individual travel patterns. The Restricted are clearly the most disadvantaged group. They are most in need of support but are at the same time less open to technical services that could disburden their everyday life. Probably, this group would benefit the most from improvements in the public transport services in terms of accessibility, safety and security.

The segmentation of the baby boomers by their future expectations was a novel aspect of the present study, and provided insight into the heterogeneity of the group. The similarities between the segments identified in this study and in previous studies using different variables and populations indicate that the current approach has good reliability. In addition, the present study had a large and representative sample, making the results highly generalisable to Danish baby boomers. The educational level of the respondents was somewhat higher than that of the general Danish population in this age group, which may have influenced the results. It can be expected that the respondents in the present study may have had somewhat better mobility resources than average which, in turn, would be reflected in their mobility behaviour and expectations. It is likely that the proportion of persons with more limited access to transport and a profile resembling the "Restricted" group would be larger in the general baby boomer population.

In the present study, we chose to focus on the future expectations as a basis for future travel demand. We based this choice on the gerontological theories on life course and continuity. This focus is a unique aspect of the present study, as the previous research has mainly focused on describing the current characteristics of the boomers instead of their future intentions. What the boomers might be doing tomorrow is a highly relevant question when forecasting the travel demand and future research should address this issue. As it comes to the accuracy of the forecasts of future behaviour, we believe that while precise forecasts are not possible, the expectations and intentions give an indication of the actual behaviour in the future. However, personal factors such as impediments in functionality or policies, such as driver license legislations or regional planning may impact the actual behaviour in the future.

In the coming years, the baby boomers will become "older road users" and will enter this group as strong consumers of the transport system with a high demand for mobility, good resources and optimistic expectations about personal mobility in old age. This will pose challenges to society, which must generate policies and plans to support these needs. However, the heterogeneity of the group is a factor that plays a part in this group's demand for travel. The differences between women and men are large and somewhat similar to those observed in older cohorts. Other subgroups of boomers can also be identified, and these differ greatly in terms of mobility resources and expectations. Thus, overly optimistic scenarios about independent boomers whose need for external support in old age will be minimal may be unrealistic. Modern social policies have increasingly emphasised individual and family responsibility rather than state responsibility to meet the needs of older people (Quine and Carter, 2006), but whether this is a feasible and reasonable solution, even for the boomers as they age, is questionable.

\section{References}

Aigner-Breuss, E., Braun, E., Schöne, M.-L., Herry, M., Steinacher, I., Sedlacek, N., Hauger, G., Klamer, M., Kriks, S. (2010) Mobilitätsszenarienkatalog Mobilitätszukunft für die Generation 55+. Mobilitätsszenarien für eine aktive Teilnahme am Verkehr unter Berücksichtigung der erforderlichen Verkehrstechnologien, retrieved from: 〈http://www.kfv.at/fileadmin/webcontent/Bereich_VM/ MOTION55_Mobilitaetsszenarienkatalog.pdf $\rangle$.

Arentze, T., Timmermanns, H., Jorritsma, P., Kalter, M.-J.O., Schoemakers, A., 2008. More grey hair-but for whom? Scenario-based simulations of elderly activity travel patterns in 2020. Transportation 35, 613-627.

Atchley, R., 1999. Continuity and Adaptation in Aging. The Johns Hopkins University Press, Baltimore, MD.

Coughlin, J.F., 2009. Longevity, lifestyle, and anticipating the new demands of aging on the transportation system. Public Works Management \& Policy 13, 301-311.

Cumming, E., Henry, W., 1961. Growing Old: The Process of Disengagement. Basic Books, New York.

Dychtwald, K., 1999. Age Power: How the 21st Century will be Ruled by the New Old. Putnam, New York, USA.

Eurostat (2011) Persons with Low Educational Attainment, by Age Group', retrieved from: 〈http://epp.eurostat.ec.europa.eu/portal/page/portal/education/data/ main_tables $\rangle$. 
Hakamies-Blomqvist, L., Henriksson, P., Anund, A., Sörensen, G. (2005) Fyrtiotalisterna som framtida äldre trafikanter [1940s cohorts as future older road users], VTI report 507, VTI, Linköping, Sweden.

Hakamies-Blomqvist, L., Siren, A., 2003. Deconstructing a gender difference: driving cessation and personal driving history of older women. Journal of Safety Research 34, 383-388.

Haustein, S., 2012. Mobility behavior of the elderly-an attitude-based segmentation approach for a heterogeneous target group. Transportation 39, 1079-1103.

Haustein, S., Hunecke, M. Kemming, $H_{\text {, }}$ 2008. Mobilität von Senioren. Ein Segmentierungsansatz als Grundlage zielgruppenspezifischer Angebote. [Seniors mobility. A segmentation approach as basis for target-group specific services]. Internationales Verkehrswesen 60, 181-187.

Hildebrand, E.D., 2003. Dimensions in elderly travel behaviour: a simplified activity-based model using lifestyle clusters. Transportation 30, 285-306.

Hjorthol, R.J., Levin, L., Siren, A., 2010. Mobility in different generations of older persons: the development of daily travel in different cohorts in Denmark, Norway and Sweden. Journal of Transport Geography 18, 624-633.

INFAS, DLR (2010) Mobilität in Deutschland 2008. [Mobility in Germany 2008]. Ergebnisbericht im Auftrag des Bundesministeriums für Verkehr, Bau und Stadtentwicklung, retrieved from: www-mobilitaet-in-deutschland.de.

Keister, L.A., Deeb-Sossa, N., 2001. Are baby boomers richer than their parents? Intergenerational patterns of wealth ownership in the United States. Journal of Marriage and the Family 63, 569-579.

Lanzieri, G. (2011) The Greying of the Baby Boomers. A Century-long View of Ageing in European Populations, Eurostat: Statistics in focus, 23/2011, retrieved from: 〈http://epp.eurostat.ec.europa.eu/cache/ITY_OFFPUB/KS-SF-11-023/EN/ KS-SF-11-023-EN.PDF $\rangle$.

Miranda-Moreno, L.F., Lee-Gosselin, M., 2008. A week in the life of baby boomers: how do they see the spatial-temporal organization of their activities and travel? Transportation 35, 629-653.

Mollenkopf, H., Marcellini, F., Ruoppila, I., Szeman, Z., Tacken, M., Wahl, H.-W. 2004. Social and behavioural science perspectives on out-of-home mobility in later life: findings from the European project MOBILATE. European Journal of Ageing 1, 45-53.

Moschis, G.P., McArthur, A., 2007. Baby Boomers and their Parents. Paramount Market Publishing, Ithaca, NY, USA.

Newbold, K.B., Scott, D.M., Spinney, J.E.L., Kanaroglou, P., Páez, A., 2005. Travel behaviour within Canada's older population: a cohort analysis. Journal of Transport Geography 13, 340-351.

OECD, 2001. Ageing and Transport: mobility needs and safety issues. Paris, France: OECD.

Ottman, P., 2010. Abbildung demographischer Prozesse in Verkehrsentstehungsmodellen mit Hilfe von Längsschnittdaten. [Integration of demographic processes into trip generation modelling based on longitudinal data]. KIT Scientific Publishing, Karlsruhe.

Páez, A., Scott, D., Potoglou, D., Kanaroglou, P., Newbold, K.B., 2007. Elderly mobility: demographic and spatial analysis of trip making in the Hamilton CMA, Canada. Urban Studies 44, 123-146.

Quine, S., Carter, S., 2006. Australian baby boomers' expectations and plans for their old age. Australasian Journal on Ageing 25, 3-8.

Rees, C., Lyth, A. (2004) Exploring the future of car use for an ageing society: preliminary results from a Sydney study. In: Paper Presented at the 27th Australasian Transport Research Forum, Adelaide, Sep-Oct 2004.

Robins, T., 1995. Remembering the future: the cultural study of memory. In: Allan, B. Allan, S. (Eds.), Theorizing Culture. An Interdisciplinary Critique After Postmodernism. UCL Press, London.

Rosenbloom, S. (1995) Travel by the Elderly. Demographic Special Reports. 1990 NPTS Report Series, US Department of Transportation, Washington DC, USA.

Rosenbloom, S., 2006. Is the driving experience of older women changing? Safety and mobility consequences over time. Transportation Research Record 1956 127-132.

Rosenbloom, S., 2007. Differences in perceptions of driving skills. Older drivers and the adult children of older drivers in the United Kingdom. Transportation Research Record 2009, 15-22.

Rosenbloom, S., Fielding, G.J., 1998. Transit Markets of the Future-The Challenge of Change. National Academy Press, Washington DC, USA.

Rosenbloom, S., Herbel, S., 2009. The safety and mobility patterns of older women: do current patterns foretell the future? Public Works Management Policy 13 338-353.

Rudinger, G., Käser, U., 2007. Smart Modes: ,Senioren als Fußgänger und Radfahrer im Kontext alterstypischer Aktivitätsmuster. Zeitschrift für Verkehrssicherheit 53 (3), 141-145.

Siren, A. (2005) Older Women's Mobility and Transportation Issues: Restraints and Regulations, Lust and Splendour. Ph.D. Thesis. University of Helsinki, Finland.

Siren, A., Hakamies-Blomqvist, L., 2005. Sense and sensibility. A narrative study of older women's car driving. Transportation Research Part F: Traffic Psychology and Behaviour 8, 213-228.

Siren, A., Hakamies-Blomqvist, L., Lindeman, M., 2004. Driving cessation and health in older women. Journal of Applied Gerontology 23, 58-69.

Statistics Denmark (2011) StatBank Denmark, retrieved from: 〈http://www.statis tikbanken.dk/statbank5a/default.asp?w=1280>.

van den Berg, P., Arentze, T., Timmermans, H., 2011. Estimating social travel demand of senior citizens in the Netherlands. Journal of Transport Geography 19, 323-331. 